Firm Performance and Modes of Innovation

Sérgio Nunes

Raul Lopes

José G. Dias

Março de 2014

WP n. ${ }^{\circ} 2014 / 01$

DOCUMENTO DE TRABALHO WORKING PAPER 


\section{Firm Performance and Modes of Innovation}

Sérgio Nunes*

Raul Lopes**

José G. Dias***

WP n. ${ }^{\circ} 2014 / 01$

DOI: 10.7749/dinamiacet-iul.wp.2014.01

1. INTRODUCTION

2. INNOVATION MODES: FROM THE ORGANIZATIONAL KNOWLEDGE TO TERRITORIAL NETWORKING

3. METHODOLOGICAL OPTIONS AND DATA

4. DIFFERENT MODES OF INNOVATION: A PROPOSAL

5. INNOVATION MODES, FIRMS' PERFORMANCE AND THE ECONOMIC CRISIS

6. CONCLUSIONS AND POLICY RECOMMENDATIONS

* Center of Applied Research on Economics and Territory Management (CIAEGT-IP), Polytechnic Institute of Tomar, Tomar, spnunes@ipt.pt

** Department of Political Economy, Instituto Universitário de Lisboa (ISCTE-IUL), DINÂMIA/CET-IUL, Lisboa.raul.lopes@iscte.pt

*** Instituto Universitário de Lisboa (ISCTE-IUL), BRU-IUL, Lisboa. jose.dias@iscte.pt 


\title{
Firm Performance and Modes of Innovation ${ }^{1}$
}

\begin{abstract}
It has been shown that firms tend to develop different modes of innovation, based on the relationship between the different types of underlying knowledge and learning processes. This paper seeks to identify different modes of business innovation, relating them to firms' innovative and economic performance, and to analyze the relationship between the different innovation modes and the economic impact of the crisis on firms' performance. These hypotheses are tested by regression and latent class models for the Portuguese population of firms, using a sample of 397 firms, classified according to technological intensity, firm size and region. Our results show three different modes of innovation in terms of the relationship between economic and innovative performance, with significant differences in terms of resilience in the face of the economic crisis. These findings lead to a reflection on innovation, competitiveness and regional policy.
\end{abstract}

Keywords: economic performance, innovation modes, innovation process, governance mechanisms, economic crisis, firms' resilience, innovation policy.

\footnotetext{
${ }^{1}$ We thank to an anonymous reviewer for valuables comments that help to improve the manuscript.

DINÂMIA'CET - IUL, Centro de Estudos sobre a Mudança Socioeconómica e o Território ISCTE-IUL - Av. das Forças Armadas, 1649-026 Lisboa, PORTUGAL 


\section{INTRODUCTION}

Different strands of the literature and international organizations have shown that firms do not innovate in the same way, identifying different behaviours of firms, both in their innovation processes and economic performance. Once different modes of innovation have been identified, we must consider the various implications for public policy and for innovation strategies. The recognition of other modes of innovation, not driven by science and technology, is of major importance in terms of policy implications. In fact, the abandonment of monolithic policies for promoting innovation (R\&D), the appreciation of different strategies in terms of competitiveness policy and the incorporation of the territorial dimension in the different public policies, are currently the main challenges for the political and economic leaders of Europe in general and each territorial actor in particular.

Taking Portugal as a case study, this paper has three main objectives: first, we will identify different modes of innovation practiced by Portuguese firms. Secondly, we will relate them to the innovative and economic performance of the firms. Finally, we will inquire into the relationship between the different modes of innovation and the impact of the economic crisis. The paper is organized into four sections. In the first section we present the theoretical and conceptual framework for identifying different modes of business innovation. The second section identifies the main methodological options for empirical analysis. We show the latent class model used and the process of building the database, the variables used, and the selection and estimation of the model. Then we outline the main results and a proposal for the definition of different modes of innovation. In section 3 we will match the different modes of innovation to the innovative and economic performance of firms. Innovation performance is measured by both one-dimensional variables (product and process innovation) and multidimensional ones. Economic performance is measured by the "growth in turnover" variable. In order to test this relationship, four econometric models are estimated, using logistic regression. We estimate another econometric model to test the relationship between modes of innovation and the current economic crisis. Finally we present the main conclusions and their political implications.

DINÂMIA'CET - IUL, Centro de Estudos sobre a Mudança Socioeconómica e o Território ISCTE-IUL - Av. das Forças Armadas, 1649-026 Lisboa, PORTUGAL 


\section{INNOVATION MODES: FROM THE ORGANIZATIONAL KNOWLEDGE TO TERRITORIAL NETWORKING}

Different methodological approaches have been applied in the identification of distinct modes of innovation (see, for example, Fitjar and Rodriguez-Pose, 2013; Gokhberg, Kuznetsova and Roud, 2012; Parrilli and Elola, 2011; Parrilli, González and Peña, 2012; Corrocher, Cusmano and Morrison, 2011; Marlon and Lambert, 2009; Žížalová, 2009; Jensen et al., 2007; Lundvall, 2007; Tödtling, Lehner and Kaufmann, 2006; Lorenz and Lundvall, 2006; Tödtling, Lehner and Trippl, 2004).

Knowledge and learning have been at the heart of every conceptual framework developed by the different approaches. Both the learning process and the knowledge associated with it may take several forms. The linkages between forms of knowledge and learning define the different modes of innovation used by firms. Jensen et al. (2007) suggest two different modes of learning and innovation: the mode based on the production and use of codified scientific and technological knowledge - Science, Technology and Innovation (STI), and the mode based on learning from experience and supported by interactive learning processes Doing, Using and Interacting (DUI). This is our conceptual starting point. We consider differentiating factors and aspects introduced by Jensen et al. (2007) as well as additional factors believed to be relevant in differentiating modes of innovation.

Lundvall (2007) and Jensen et al. (2007) highlight the role of knowledge in the innovation process, recognizing the importance of collective learning processes in knowledge production. The knowledge produced and accumulated in this way - by collective learning processes - should not be confused with scientific knowledge from the traditional system, assigned mostly to large firms and the scientific research system in particular. Innovation occurs in all sectors, whether it involves technology to a greater or lesser extent and is more or less knowledge-intensive. The knowledge relevant for innovation derives not only from the traditional scientific system, but also from the collective learning processes associated with various contexts and the (formal and informal) interaction of the various actors in them (Nunes, 2012; Nunes and Lopes, 2012b). As Hudson stresses (1999: 62) "The emphasis now is therefore upon recognizing that innovation is an interactive process that involves the synthesis of different types of knowledge rather than privileging the formal scientific knowledge of the $R \& D$ laboratory over other forms of knowledge" and "creating dense horizontal flows of knowledge and information within, and vertical flows of knowledge and information between, the various functional divisions of the company, while opening the ears of those involved within the company to voices from outside its boundaries" (op. cit: ibid).

DINÂMIA'CET - IUL, Centro de Estudos sobre a Mudança Socioeconómica e o Território ISCTE-IUL - Av. das Forças Armadas, 1649-026 Lisboa, PORTUGAL 
Jensen et al. (2007) argue that there is a tension between the learning and innovation mode based on the production and use of codified scientific and technological knowledge and the experience-based interactive learning mode. This tension has led to a bias on the part of politicians and researchers in favour of the science-based mode, seeing innovation as being mostly linked to formal R\&D processes, particularly in science-based industries and high technology. Jensen et al. (2007: 104) introduced a 2 x 2 typology of innovation models (Table 1). Research on innovation has paid special attention to cells 1 and 4 , and policymakers have concentrated their efforts in cell 4.

Table 1 - Dimensions of the innovation modes

\begin{tabular}{l|c|c}
\hline & Low-tech sectors & High-tech sectors \\
\hline DUI Mode & 1 & 2 \\
\hline STI Mode & 3 & 4 \\
\hline
\end{tabular}

Source: Jensen et al. (2007: 104)

This author shows that different types of firms adopt both innovation modes to varying degrees, and that the most innovative firms are those which combine the two. Interactions between technological innovations in hardware and software on the one hand, and between human resources, organizational change and networking on the other, are both crucial to the process of innovation and the rate at which innovations are transformed into economic performance. The results obtained by the authors support the assertion that "It is the firm that combines a strong version of the STI-mode with a strong version of the DUI-mode that excels in product innovation (Jensen et al., 2007: 685). These results confirm the argument that innovation and collective learning processes cut across the entire economy (both in terms of high and low technology) and that firms' capacity to innovate is heavily dependent on combinations of these two "pure" modes and not just on the traditional way, supported by science and codified into patents.

Taking this seminal work as our starting point, we have added four relevant conceptual aspects of the innovation process: the context of knowledge access (different external contexts, from local to global), formal and informal mechanisms of interaction and modes of learning associated with controlling the dynamics of the innovation process, the radicalness of the innovation process (incremental to radical innovation) and the predominance of the innovation process activities in firms (knowledge production, knowledge transformation and product placement in the market). When a process of innovation is supported mainly by the dynamics of cooperation, the territory, the various networks of knowledge and interaction mechanisms (especially mechanisms of an informal nature) play a key role in the effectiveness of the 
innovation process (see Fuller-Love, 2009; Nunes, 2012; Nunes and Lopes, 2012a and Nunes and Lopes, 2012b) and should be taken into account as differentiated aspects of the innovation modes. Additionally, innovation modes should not be seen as independent of the type of innovation that firms have introduced into the economy and the activities that drive their innovation processes.

In summary, Table 2 identifies the main factors and aspects that in our synthesis contribute to defining the different modes of innovation.

Table 2 - Conceptual aspects of innovation modes

\begin{tabular}{l|l|l}
\hline Knowledge type & \multicolumn{1}{|c}{ STI Mode } & \multicolumn{1}{c}{ DUI Mode } \\
\hline Learning type & $\begin{array}{l}\text { Analytical, codified and explicit, } \\
\text { science-base: know-why }\end{array}$ & $\begin{array}{l}\text { Tacit and contextual: Know-how and } \\
\text { know-who }\end{array}$ \\
\hline Innovation type & $\begin{array}{l}\text { Made mostly from formal R\&D } \\
\text { processes }\end{array}$ & $\begin{array}{l}\text { Informal interaction processes: learning } \\
\text { based on experience, by doing, by using, } \\
\text { by interacting; }\end{array}$ \\
\hline $\begin{array}{l}\text { Innovation activities } \\
\text { Knowledge context }\end{array}$ & $\begin{array}{l}\text { Knowledge production } \\
\text { Knowledge transformation }\end{array}$ & $\begin{array}{l}\text { Knowledge transformation } \\
\text { Product placement in the market }\end{array}$ \\
\hline $\begin{array}{l}\text { Governance strategy of } \\
\text { knowledge } \\
\text { management and } \\
\text { promotion of the } \\
\text { innovation process }\end{array}$ & $\begin{array}{l}\text { Sharing internally, in the } \\
\text { organization, of knowledge from } \\
\text { a broad base of general and } \\
\text { codified knowledge }\end{array}$ & $\begin{array}{l}\text { Restricted and territorial } \\
\text { various departments of the organization } \\
\text { and external actors, building structures } \\
\text { and networks of relationships that } \\
\text { enhance learning in specific ways: } \\
\text { project teams, problem-solving groups, } \\
\text { job rotation, proximity to customers }\end{array}$ \\
\hline $\begin{array}{l}\text { jeveloped in-house - in-house } \\
\text { netwol - or in a closed business }\end{array}$ & $\begin{array}{l}\text { Innovation activities mainly developed in } \\
\text { cooperation - networking model }\end{array}$ \\
\hline
\end{tabular}

Source: Authors' own compilation, based on Lundvall (2007), Jensen et al. (2007), Asheim and Gertler (2005), Nunes (2012), Nunes and Lopes (2012a) and Nunes and Lopes (2012b)

\section{METHODOLOGICAL OPTIONS AND DATA}

As a way of identifying different modes or ways of developing innovation activities from certain behaviours of firms, we used a latent class model, the methodology also used in Jensen et al. (2007). In simple terms, the latent class analysis can be seen as a factorial analysis technique of categorical variables in which the latent variables or factors are discrete. The different modes of innovation are impossible to identify, it being necessary to seek to understand them on the basis of a set of characteristics and behaviours of different firms, but these are identifiable. The following diagram helps to illustrate the main idea behind this type of model. The latent variable $\mathrm{Z}$ is discrete with $\mathrm{S}$ categories or groups, i.e., $\mathrm{Z}=1,2, \ldots, \mathrm{S}$, that cannot be observed directly, but can be identified from its manifestations: $Y_{=} Y_{1}, Y_{2}, \ldots, Y_{J}, J$ 
being the number of manifest variables. Moreover, L concomitant variables are used in cluster profiling: $\mathrm{X}=\mathrm{X}_{1}, \mathrm{X}_{2}, \ldots \mathrm{X}_{\mathrm{L}}$

Figure 1 - Latent Class Model

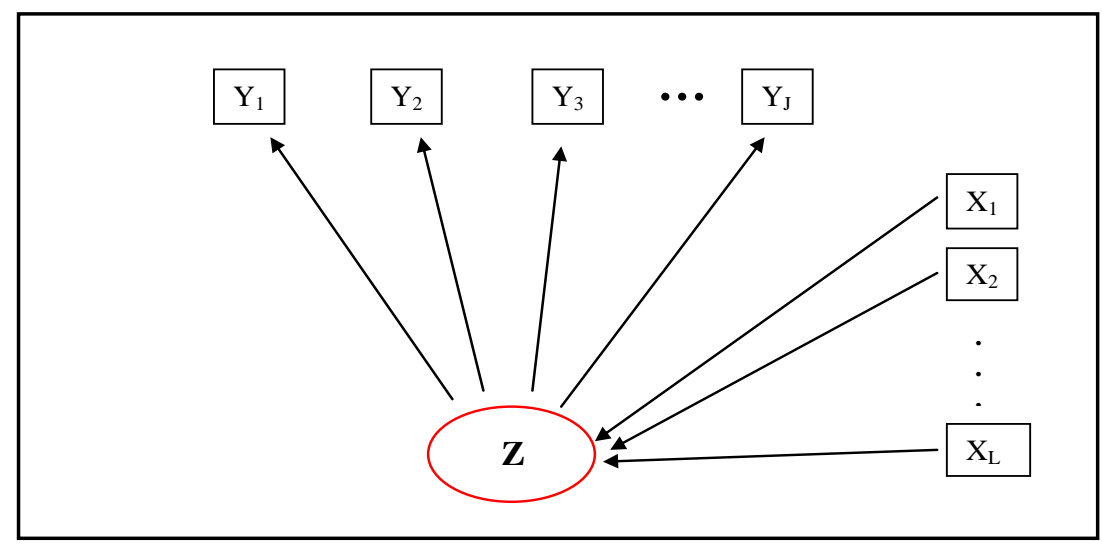

We may interpret Figure 1 as follows:

- The conditional probability $P(Z=s \mid X)$ : probability of the observation belonging to the cluster $Z=S$, since the firm has the characteristic $X$, which represents a model of the probit/logit type;

- The conditional probability $P(Y \mid Z=s)$ : probability of observing the behaviour of $\mathrm{Y}$, given that the firm is in cluster $Z=s$.

For a more detailed discussion of this statistical model we suggest a reading of McCutcheon (1987) or Clogg (1981).

The database used in this article resulted from a sample who is representative of the 981 Portuguese firms that satisfy the following criteria: turnover of over $€ 1$ million in 2008 and at the same time an increase in turnover of at least 5\% between 2007 and 2008. This choice was made with the aim of identifying the more dynamic group of firms from the point of view of their economic performance. It is possible to stratify the universe according to the following variables:

- Levels of technological intensity and knowledge services: high-technology (HT), medium-high technology (MHT), medium-low technology (MLT) and low-technology (LT). We also took knowledge services (KS) firms into account. This typology was chosen because it is the most commonly used in the international literature, mainly by reference entities such as the OECD and the European Union;

- Firms' size - classified into Micro (0-9), SMEs (10-250) and large firms (> 250) by number of employees (2008);

DINÂMIA'CET - IUL, Centro de Estudos sobre a Mudança Socioeconómica e o Território ISCTE-IUL - Av. das Forças Armadas, 1649-026 Lisboa, PORTUGAL 
- NUTS III (Greater Lisbon and Setubal Peninsula, Pinhal Litoral and Greater Porto). These 4 NUTS correspond to the Portuguese metropolitan areas (natural habitat of innovation) and Pinhal Litoral, one of the non-metropolitan areas repeatedly referenced as having a strong innovative dynamics. Therefore, this variable seeks to capture the differences in the regional structure under analysis.

As it is not financially possible to carry out an investigation of the entire population, a representative sample was subsequently chosen. This was obtained by stratification and proportional affixation, from telephone interviews conducted by an independent specialized company in late 2010 and early 2011. The survey included key components in line with the theoretical framework developed, covering the following aspects: description of the firm, innovation activities, internal resources and performance, activities involving different modes of innovation, external resources, types of proximity and aspects related to the crisis in the innovation process. This produced a database containing 397 observations, representative of the population on which the statistical and econometric work of this paper is based.

Methodologically the latent class model was applied to the database previously mentioned, with the manifest variables - the 12 variables and categories listed in Table 3, having been selected as inputs.

Table 3 - Manifest variables and categories

\begin{tabular}{l|l|l}
\multicolumn{1}{c|}{ Variables } & \multicolumn{1}{c}{ Categories } & \multicolumn{1}{c}{$\begin{array}{c}\text { Dimension of the } \\
\text { innovation process }\end{array}$} \\
\hline $\begin{array}{l}\text { 1. Multidisciplinary groups } \\
\text { 2. Quality circles/groups }\end{array}$ & Likert (1 - Irrelevant; 5 - Fundamental) & \\
3. Collective proposals & Likert (1 - Irrelevant; 5 - Fundamental) & \\
4. Integrated functions & Likert (1 - Irrelevant; 5 - Fundamental) \\
5. Less well differentiated groups & Likert (1 - Irrelevant; 5 - Fundamental) & \\
6. External cooperation & Likert (1 - Irrelevant; 5 - Fundamental) & Organizational Learning \\
7. R\&D department & Likert (1 - Irrelevant; 5 - Fundamental) & \\
8. External financing & Likert (1 - Irrelevant; 5 - Fundamental) & \\
\hline 9. Innovation new to the market & Likert (1 - Irrelevant; 5 - Fundamental) & \\
\hline 10. Predominance of innovation & Likert (1 - Irrelevant; 5 - Fundamental) & Radicalness of innovation \\
\hline activities & Knowledge production & \\
\hline 11. Knowledge context & Knowledge transformation & Innovation activities \\
\hline 12. Learning and interaction \\
mechanisms
\end{tabular}

Source: Authors' own compilation

DINÂMIA'CET - IUL, Centro de Estudos sobre a Mudança Socioeconómica e o Território ISCTE-IUL - Av. das Forças Armadas, 1649-026 Lisboa, PORTUGAL 
To measure the different modes of innovation, Jensen et al. (2007) used a set of binary variables (see Table 3, variables 1 to 8 ). It should be noted, however, that the variables they used essentially reflect the internal context of innovation within firms (that is to say, the organizational learning associated with the DUI mode), with the exception of those variables which express cooperation with external clients and researchers (variables associated with the STI mode). In our model, we also took into account certain variables (from variable 9 to variable 12) associated with how radical the innovation was (its radicalness), the types of knowledge used in the innovation process, the context of the knowledge used, and interaction and learning mechanisms. In this way we sought to include the various elements contained in the description of modes of innovation set out in Table 2. Our aim was to define a typology of clusters to match the different modes of innovation, based on 12 manifest variables. As concomitant (or descriptive) variables - that don't affect the cluster formation - we adopted technological intensity, NUTS III regions and firm size (see Table A1 in the Appendix). Table 4 contains a suggested conceptual scheme for the relationship between the variables used and the two "pure" modes of innovation.

Table 4 - Variables and a conceptual proposal for two "pure" innovation modes

\begin{tabular}{|c|c|c|}
\hline & DUI Mode & STI Mode \\
\hline Organizational Learning & ++ & + \\
\hline \multicolumn{3}{|l|}{ Radicalness } \\
\hline Incremental & ++ & + \\
\hline Radical & + & ++ \\
\hline \multicolumn{3}{|l|}{ Predominance of Innovation Activities } \\
\hline Knowledge production & + & ++ \\
\hline Knowledge transformation & ++ & ++ \\
\hline Product placement in the market & ++ & + \\
\hline \multicolumn{3}{|l|}{ Knowledge Context } \\
\hline Territorial & ++ & ++ \\
\hline Global & + & ++ \\
\hline \multicolumn{3}{|l|}{ Learning and Interaction Mechanisms } \\
\hline Formal & + & ++ \\
\hline Informal & ++ & + \\
\hline
\end{tabular}

Source: Authors' own compilation

(++: more predominance; +: less predominance)

Using the Latent Gold 4.5 software, we estimated each model for different starting values in order to minimize the effect of local optima. Models from one to four latent classes were estimated. Model selection should be based on the optimum number of latent classes needed to retrieve population heterogeneity and to enable the researcher to interpret the data in case of doubt. Table 5 contains the information criteria: BIC - Bayesian Information Criterion 
(Schwartz, 1978) and AIC - Akaike Information Criterion (Akaike, 1974). Minimum values of BIC and AIC identify the best model.

Table 5 - Information criteria

\begin{tabular}{c|c|c|c|c|c}
\hline Models & Clusters & Log-likelihood & BIC & AIC & Parameters \\
\hline Model 1 & 1-Cluster & -5643.7 & 11514.8 & 11363.4 & 38 \\
Model 2 & 2-Cluster & -5468.5 & $\mathbf{1 1 4 4 5 . 6}$ & 11106.9 & 85 \\
Model 3 & 3-Cluster & -5414.6 & 11619.1 & $\mathbf{1 1 0 9 3 . 2}$ & 132 \\
Model 4 & 4-Cluster & -5370.4 & 11812.0 & 11098.9 & 179 \\
\hline
\end{tabular}

If we look at the information criteria shown in Table 5, there is no clear choice as to what the right number of clusters should be. The BIC criterion would lead us to choose model 2, while the AIC criterion would lead us to choose model 3: the pattern does not point in the same direction. In the literature it has been argued that the BIC criterion is restrictive as to the choice of the number of clusters, while the AIC criterion is considered less conservative (see, for example, McLachlan and Peel, 2000). In this case, the choice depends on the researcher's interpretation of the clusters. The choice fell on model $3-3$ clusters - given that, compared to Model 2, it yields an additional cluster which identifies a group of firms whose characteristics are relevant to the ongoing discussion, as we shall see below.

Table A2 in the Appendix shows in detail the results of the estimates of the latent class model, taking into account the three clusters mentioned. The results allow us to identify the conditional probability of a firm engaging in a particular form of behaviour, knowing that it belongs to a particular cluster. The second row of all tables refers to the size of each cluster. Cluster 1 contains 67\% of firms, Cluster $220 \%$ and Cluster 3 13\%. The p-value column shows that all manifest variables are considered statistically significant, and that helps to explain the differences found. In general terms, it can be argued that since there are other variables in the model, this variable adds significant explanatory power. The last column shows proportions of the sample as a whole. By comparing the information in previous tables (profile information from the outputs) with additional information obtained through Latent Gold 4.5 (probmeans and graphical representations of both), we can characterize and identify a label for each latent class, representing distinct modes of innovation. The labelling and profiling of latent classes is pursued in next section.

DINÂMIA'CET - IUL, Centro de Estudos sobre a Mudança Socioeconómica e o Território ISCTE-IUL - Av. das Forças Armadas, 1649-026 Lisboa, PORTUGAL 


\section{DIFFERENT MODES OF INNOVATION: A PROPOSAL}

Based on the analysis of the previous tables, we propose three general modes of innovation, associated with each of the clusters identified by the three latent class model.

Table 6 - Modes of Innovation - Main Features

\begin{tabular}{l|ccc}
\hline & Cluster 1 & Cluster 2 & Cluster 3 \\
\hline MANIFEST VARIABLES & Low Learning DUI & Moderate DUI/STI & Moderate DUI \\
\hline Organizational Learning & ++ & + & + \\
R\&D Department & + & + & + \\
External Cooperation & & ++ & \\
External Financing & + & + & + \\
Incremental to Radical innovation & + & + & ++ \\
Market-Transformation-Production & M & M-P-T & M-T \\
Knowledge Context & G & T & G \\
Learning and interaction mechanisms & I & I & F-I \\
\hline CONCOMITANT VARIABLES & & & \\
\hline Level of technological intensity & Low Learning DUI & Moderate DUI/STI & Moderate DUI \\
\hline Low technology & ++ & + & + \\
Medium-low technology & ++ & ++ & ++ \\
Medium-high technology & + & ++ & ++ \\
High technology & + & + & + \\
Knowledge services & + & ++ & + \\
\hline Nuts III regions (not significant) & & & + \\
\hline Greater Lisbon and Setubal Peninsula & ++ & ++ & + \\
Greater Porto & + & ++ & + \\
Pinhal Litoral & + & + & + \\
\hline Firm size & ++ & & + \\
\hline Micro & + & & + \\
SME & & & + \\
Large & + & & + \\
\hline Source: Authors' own compilation & & & + \\
\hline
\end{tabular}

Source: Authors' own compilation

Then characteristics of each of these three innovation modes are summarized below.

\section{Mode 1 - Low Learning DUI mode of innovation}

This cluster covers about $67 \%$ of the sample firms. In terms of characterization variables, this is a group that hosts essentially SMEs located in the Lisbon metropolitan area. As subsequent results show, this cluster is characterized by firms with low innovative intensity, whose 
innovation process is basically of the experimental-incremental type i.e. in the line of the DUI mode. Because this group has similar features to the corresponding group defined by Jensen $e t$ al. (2007), we call it the "Low Learning DUI" innovation mode.

The main innovative features of these firms' innovation mode include the following:

- These are firms that use low technology (LT) or medium-low technology (MLT), and whose innovation activity is restricted overwhelmingly to "Product Placement in the Market";

- In terms of radicalness of innovation, these are firms which produce mainly incremental innovations (product and process improvement). To this end they value global knowledge over territorial knowledge. This would explain why they do not attach much importance to external cooperation because, apart from market exchanges, their mechanisms of interaction are mostly informal and confined to the sphere of the firm's own internal organization;

- Given the nature of the mode of innovation practiced by these firms, about $60 \%$ of them do not attach much importance to the existence of a R\&D department. In contrast, they do value the process of organizational learning, through intensive use of multidisciplinary teams, quality circles, suggestions made by employees collectively, and integrated functions.

This cluster produces some unexpected results, in particular the fact that these firms mainly use global knowledge, practice innovation which is in some degree radical but, in contrast, do not value external cooperation and rely greatly on informal interaction. This apparent contradiction can be explained by the following facts. First, these are firms in which innovation mainly takes the form of placing a product on the market, which may lead to overestimation of the amount of global knowledge involved and of how radical the innovation is (self-assessment of knowledge and technology embodied in the product sold). Secondly, the process of interactive learning in these firms occurs mainly within the firm, and because these firms are small, their relationships with others will mainly be of an informal nature. Finally, these firms benefit because they operate in a dynamic market with strong knowledge and information flows, like the Lisbon Metropolitan Area. This territorial market framework could cause the firms to benefit from informal interaction processes without properly valuing the corresponding interactions with their surrounding context, even bearing in mind the informal nature of such relationships. Operating in a very dynamic metropolitan context firms tend to value the most radical types of innovation as a way to differentiate themselves from their competitors.

DINÂMIA'CET - IUL, Centro de Estudos sobre a Mudança Socioeconómica e o Território ISCTE-IUL - Av. das Forças Armadas, 1649-026 Lisboa, PORTUGAL 


\section{Mode 2 - Moderate DUI/STI mode of innovation}

This cluster accounts for around $20 \%$ of the sample firms. These are firms that we call Moderate Innovators, combining practices inherent to the DUI mode with procedures specific to the STI mode. As Jensen et al. (2007) also concluded, in our test the cluster that combines two modes of innovation is that which reveals the strongest performance, as discussed in detail in the next section. In terms of characterization variables, this is a group consisting predominantly of SMEs located in a metropolitan context (either in Lisbon or Porto). In addition to SMEs, it is important to highlight the significance of micro firms in this cluster. It is moreover the only one where the probability of finding firms of this size is notably higher than in the other clusters. In general, firms in this group have a relatively higher level of technological intensity compared to those identified in the previous mode of innovation, with predominantly industrial firms of medium technological intensity (MLT and MHT), or firms operating in the field of knowledge services (KS).

As regards the innovation mode, these firms are noteworthy for:

- The fact that, as in the previous cluster, their innovation is primarily incremental; they do not pay particular attention to the existence of internal R\&D departments and prefer informal mechanisms of interaction and learning.

- Unlike the previous mode of innovation, firms now tend to combine "placing the product on market" with the practice of transformation and even knowledge production, indicating stronger innovative performance.

- Another aspect clearly distinguishing this cluster from the previous one is the fact that in this innovation mode firms place a high value on territorial knowledge absorbed through external cooperation, and see these relations as being "very important." Thus informal mechanisms of interaction now occur in the firm's connections with its surrounding territory, rather than inside the firm as in the previous mode of innovation.

- In terms of organizational learning, firms in this cluster attribute a lower value to organizational learning, and this is mainly associated with "functional integration" within the firm.

Also in this case the presence of STI mode characteristics (such as the importance attributed to the "transformation" and even "production" of knowledge) appears to contradict the emphasis on informal mechanisms of regional interaction rather than efforts in R\&D. However, if we consider that these firms are often micro-businesses and the knowledge that they mobilize for innovation allows no more than incremental innovations, we will be better able to understand the importance of the territorial location context (the two metropolitan areas) and its learning

DINÂMIA'CET - IUL, Centro de Estudos sobre a Mudança Socioeconómica e o Território ISCTE-IUL - Av. das Forças Armadas, 1649-026 Lisboa, PORTUGAL 
mechanisms by networking. In any case, it should not be forgotten that this cluster combines two modes of innovation, but with a clear predominance of an experimental type of DUI.

Thus we call this cluster the "Moderate DUI/STI" innovation mode.

\section{Mode 3 - Moderate DUI mode of innovation}

Cluster 3 encompasses around $13 \%$ of the sample firms. It is the smallest cluster, and has intermediate characteristics when compared to the two previous clusters. Like cluster 1 it is essentially made up of SMEs (and some large firms). These are industrial firms that predominantly use mid-range technology, as in cluster 2 . They also share with cluster 2 a type of innovative activity where "placing the product on the market" is combined with the "transformation" of knowledge (but not the "production of knowledge" that is sometimes seen in cluster 2). Finally, as with cluster 1, this mode mobilizes global rather than local knowledge, but neither values the mechanisms of interaction and learning outside the firm (as in cluster 2) nor internal mechanisms as highly as firms in the first cluster. We should note that in this cluster most interactions are governed by formal mechanisms, despite the fact that informal mechanisms are also significant. The fact that the firms in this group did not particularly value organizational learning or external cooperation could mean that the innovation activity of these firms is essentially a mercantile interaction process, which is consistent with the nature of the activity of innovation (market-transformation) and accounts for the relative importance of formal mechanisms in this innovation mode.

Thus we call this cluster the "Moderate DUI" innovation mode.

In summary, the analysis allowed us to identify three groups of firms, with three different modes of innovation. Whilst none of the identified clusters falls into intense modes of innovation, they typify behaviours of business innovation, and with significant differences between them. Among these we highlight, on the one hand, the emphasis on intra-organizational learning processes, and, on the other hand, the value attributed to (formal and informal) networking relationships with actors outside the firm, especially those located in the same territorial context (hence it is not surprising that we are analyzing firms predominantly located in a metropolitan environment which is particularly rich in information flows and knowledge). The low level of technological complexity associated with the activity of the firms in the study accounts for the lower importance that all clusters attribute to the existence of a R\&D department. On the other hand, this means that firms can engage in innovation processes without external financing being critical to them, which in turn explains the low importance attributed to this factor by most firms in the various clusters.

DINÂMIA'CET - IUL, Centro de Estudos sobre a Mudança Socioeconómica e o Território ISCTE-IUL - Av. das Forças Armadas, 1649-026 Lisboa, PORTUGAL 


\section{INNOVATION MODES, FIRMS' PERFORMANCE AND THE ECONOMIC CRISIS}

This section seeks to determine whether any relationship can be established between the different innovation modes identified and the economic and innovative performance of firms. In addition, we will attempt to analyze the relationship between different modes of innovation and the impact of the actual international economic crisis on firms. Table A3 sets out all the variables used in estimations ${ }^{2}$ (please see the Appendix).

\section{Innovation Modes and Innovative Performance}

Three econometric models were used to test the relationship between innovation modes and innovation performance. The first model seeks to test this relationship by taking product innovation as the dependent variable.

We estimated Model 1 and Model 2 by measuring innovative performance using two variables concerning innovation output: if firms have brought to market product innovations and process innovations in the last five years. We introduced these two output innovation variables as dependent variables. The innovation modes defined in the previous section were used as independent variables.

Model 1 and Model 2 were estimated using logistic regression, according to the nature of the dependent variable. We computed product and process innovations separately against the innovation modes. We consolidated the estimation results in Table A4 (please see Appendix). The estimates of both models show that as firms go from the "Low learning DUI" to the "Moderate DUI/STI" innovation mode, the probability of bringing new products to market increases, in marginal terms, by $22.3 \%$ and $48.5 \%$ in the innovation process. In summary, we can state that in terms of product and innovation process, the "Moderate DUI/"STI" innovation mode allows firms to achieve better innovative performance.

As we know, innovative performance is a multidimensional phenomenon, and if possible we should try to measure this performance more broadly. In Model 3 we use an aggregate measure of innovative performance, incorporating some of that diversity. Based on business survey data, we construct a new variable - "Aggregate Innovation Performance". We take four types of innovation outputs: product, process, organization and patent introduction. We asked firms which type of innovation they had brought to market in the last five years. Here we are dealing with an ordinal variable that ranges from "zero" to "four" types of innovation. We take this variable as the dependent variable and the innovation modes as the independent

\footnotetext{
${ }^{2}$ All econometric work in this section was performed with Stata 10.1 .

DINÂMIA'CET - IUL, Centro de Estudos sobre a Mudança Socioeconómica e o Território ISCTE-IUL - Av. das Forças Armadas, 1649-026 Lisboa, PORTUGAL Tel. 210464031 - Extensão 293100 E-mail: dinamia@iscte.pt www.dinamiacet.iscte.pt
} 
variable. Model 3 was estimated using ordered logistic regression, according to the nature of the dependent variable. The results can be seen in table A4 in the Appendix.

Based on these results, it can be said that as firms move from the " Low learning DUI " to the "Moderate DUI/STI" innovation mode, the probability in marginal terms of achieving stronger innovation performance increases (the marginal effect is $26.1 \%$ for the fourth level, $10.5 \%$ for the last one). As in previous models, the results seem to suggest that the "Moderate DUI" mode produces slightly lower innovation performance than the reference mode, although this outcome would not be statistically significant. We can conclude that, whether we analyze innovation performance through one-dimensional or multidimensional variables, the "Moderate DUI/STI" innovation mode always achieves better results.

\section{Innovation Modes and Economic Performance}

Model 4 attempts to capture the economic performance of firms through the growth of turnover (sales volume) between 2007 and 2008, classifying firms into 6 levels. As independent variable we use our innovation modes.

Model 4 was estimated using ordered logistic regression, according to the nature of the dependent variable. The results are shown in Table A4 (please see Appendix). As in previous models, the results seem to suggest that the "Moderate DUI/STI" mode allows firms to increase the probability of achieving stronger growth in turnover. In summary, we can say that the "Moderate DUI/STI" innovation mode also allows firms to increase their probability of falling into the category of firms which achieve stronger economic performance. We also estimated the previous models for each of the control variables described previously. The main estimation results (taking only the statistically significant results) are listed in table A5 (please see Appendix). The results show that, in general, the "Moderate DUI/STI" innovation mode performed better than the other modes of innovation.

\section{Innovation Modes and the impact of economic crisis on firms innovation}

Among other insights, Nunes and Lopes (2013: 6) found empirical evidence that most firms $(65 \%)$ in our sample (those we used in this paper) recognize that the economic crisis has had a negative impact on their innovation processes. Secondly, firms use multiple channels and interaction mechanisms to obtain external knowledge, and these knowledge networks were revealed as an important way of managing the impact of the crisis. Finally, firms which suffered less from the economic crisis are the most dynamic ones (in terms of economic and innovative performance), particularly those whose innovation processes are based on strong networking interaction; as a corollary of the importance of networking, the territorial context plays a significant part in reducing the impact of the crisis on firms' innovation processes. Given these results, we must analyze whether there is a difference in the impact of the economic crisis on

DINÂMIA'CET - IUL, Centro de Estudos sobre a Mudança Socioeconómica e o Território ISCTE-IUL - Av. das Forças Armadas, 1649-026 Lisboa, PORTUGAL 
firms depending on the mode of innovation practiced. That is precisely the objective of this section.

Model 5 is designed to help us with this task and takes as the dependent variable the "Impact of Crisis on Innovation." This is an ordinal variable which can take three values: "1" if the firm indicated that the impact of the crisis was of "low importance" for their innovation process, " 3 " if the firm indicated that the impact of the crisis was "very significant" and "5" if the answer was "fundamental". The dependent variable is the same as in the previous models. Model 5 was estimated using ordered logistic regression, according to the nature of the dependent variable. The results are shown in Table A4 (please see Appendix).

The results suggest that if a firm practices the "Moderate DUI/STI" innovation mode, the probability of its feeling the impact of the economic crisis is lowered. More precisely, in terms of marginal effects, if a firm practices the "Moderate DUI/STI" innovation mode comparing it to the reference mode - the probability that the firm will respond to the effect that the impact of the crisis is "low relevance" increases by $16 \%$ and, at the same time, the probability that the firm will respond that the impact of the crisis is "Fundamental" decreases by about $10 \%$. In other words, practicing the "Moderate DUI/STI" innovation mode gives firms greater resilience when dealing with the impact of the economic crisis.

\section{CONCLUSIONS AND POLICY RECOMMENDATIONS}

Our analytical work allows us to draw two types of conclusion. One relates to the innovation strategy adopted by firms, the other to the implications of these different strategies on firms' performance. Of a different order are the conclusions to be drawn and the lessons to be learned in terms of guidance for innovation and competitiveness policy. As far as strategy is concerned, the results show that firms do not all innovate in the same way. The three modes of innovation that we found in the sample of firms in this study are a good illustration, in that they all have very different characteristics. It is important to emphasize that it is neither firm size nor the technology standard used which distinguishes innovation modes. Firms innovate in different ways depending on their behavioural strategies, and these cut across things like technology and size. Our results show that in certain circumstances even micro-enterprises may be more innovative than other firms.

Regarding the relationship between innovation modes and performance, the results obtained are unambiguous: the more complex modes of innovation (i.e. those not limited to bringing products to market, but involving transformation and even production of knowledge,

DINÂMIA'CET - IUL, Centro de Estudos sobre a Mudança Socioeconómica e o Território ISCTE-IUL - Av. das Forças Armadas, 1649-026 Lisboa, PORTUGAL 
and which value networking with actors outside the firm, especially at a territorial level), produce superior performance on three levels. These firms have higher innovation indicators, better economic results, and increased resilience in the face of the current economic crisis.

In fact, the modes of innovation identified in the sample of Portuguese firms we studied showed that, in all three analytical dimensions, the mode of innovation we call Moderate DUI/STI (cluster 2) produces better results than any of the others. Similarly, the Low Learning DUI innovation mode consistently produces the worst results in all analytical aspects.

This means that the firms on which the economic crisis has had less of an impact are the most dynamic ones (in terms of economic and innovative performance), particularly those whose innovation processes are supported by strong networking interaction. As a corollary to the importance of networking, the territorial context plays a strong role in reducing the impact of the crisis on firms' innovation processes.

The results we obtained confirm the essential conclusions Jensen et al. (2007) drew from the empirical evidence in Denmark: the most successful firms are not those employing "pure" modes of innovation, but rather those which adopt innovation strategies blending typical elements of the science and technology (STI) mode with the learning by doing, using and interacting practices characteristic of the DUI innovation mode.

This convergence of results seems to us to be of major importance, because it is associated with a number of very specific factors:

- The fact that, as far as we could determine, this is the first work that replicates, in a different context, the methodology of latent class analysis used by Jensen et al. (2007), thus allowing direct comparison of results;

- The fact that our sample is very different from that analyzed by Jensen et al. (2007). Reflecting the difference in context between Denmark and Portugal, $67 \%$ of our sample (cluster 1) has low innovation capacity (only 31\%, less than half, in the case of Denmark); our study did not reveal any pure mode of innovation STI (30\% in case of Jensen et al. (2007)). Incidentally none of the modes that we have identified is associated with firms using "high-tech," and it is only marginally active in "mediumhigh technology" or "knowledge services". Our sample shows average levels of technological intensity, or even "low-tech," as with the mode of innovation with poor results (low learning DUI cluster). Despite these differences, the relative percentages for the "Moderate DUI Mode" (13\%) and "Moderate DUI/STI" (20\%) are not significantly different from the corresponding percentages found in Denmark by Jensen et al. (2007) (18\% and 13\%, respectively).

DINÂMIA'CET - IUL, Centro de Estudos sobre a Mudança Socioeconómica e o Território ISCTE-IUL - Av. das Forças Armadas, 1649-026 Lisboa, PORTUGAL Tel. 210464031 - Extensão 293100 E-mail: dinamia@iscte.pt www.dinamiacet.iscte.pt 
- The marked convergence is further strengthened by the fact that in our study we did not confine ourselves to replicating the methodology of Jensen et al. (2007), but have added new conceptual and analytical aspects, both in terms of defining the modes of innovation and in terms of performance analysis. The results remain consistent with those obtained by Jensen et al. (2007).

It is our belief that our conceptual contribution, incorporating components consistent with the origins of the innovation process presented in the international literature, will help consolidate a broader theoretical framework, one which will thus have greater explanatory power, for the definition of the different innovation modes, with the political consequences resulting therefrom for each country, region and firm. In this case, they are competitiveness policy, innovation policy which underpins competitiveness, and regional policy, which gives territorial cohesion and relevance to those policies. In particular, in the Portuguese case, we believe that our results show the need to consider the following four challenges in the political arena.

First, while not neglecting the importance of technological upgrading, the central concern of traditional innovation policies, priority attention should be given to the factors which help businesses operating in medium and low technology segments to innovate. In particular, it is important to encourage the innovative potential of micro-enterprises and SMEs.

Secondly, without prejudice to the centrality of knowledge production dynamics, or even the "simple" transformation which supports knowledge innovation, it is important to acknowledge the economic impact of incremental innovation, particularly when it comes to innovative features of modes which combine DUI and STI.

Thirdly, the results shown here, reinforced by those obtained in Nunes and Lopes (2012a and 2012b) indicate that the territorialisation of innovation and competitiveness policies may make a major contribution to the effectiveness of public policies in this area. Results repeatedly show that territory is a key factor in the dynamics of innovation. Indeed, innovation modes based on territorial networking are seen to be more robust ways of encouraging innovation and, by extension, improved economic performance. Consequently, the promotion of dynamic specialization based on regional clusters, combined with active public intervention in fostering territorial governance networks for innovation, should be central objectives of regional development policy. In particular, such a policy should not underestimate the role of informal mechanisms of interaction and social networks of territorial origin.

Finally, the relationship, not yet established in the literature, between innovation modes and firms' (and by extension the territorial context's) resilience in the face of the economic crisis should contribute to reflection on how policymakers can best face up to today's problems.

DINÂMIA'CET - IUL, Centro de Estudos sobre a Mudança Socioeconómica e o Território ISCTE-IUL - Av. das Forças Armadas, 1649-026 Lisboa, PORTUGAL 


\section{REFERENCES}

Akaike, H. (1974) - “A new look at the statistical model identification”, IEEE Trans. Automatic Control, AC-19(6), 716-723.

Asheim, Bjorn e Gertler, Meric (2005) - "The Geography of Innovation: Regional Innovation Systems", in Fagerberg, J., Mowery, D. e Nelson, R. (Eds.) - The Oxford Handbook of Innovation. Oxford University Press. United States. ISBN: 978-0-19-926455-1, p. 291-317.

Clogg, C. C. (1981) - "Latent class models for measuring", in R. Langeheine \& J. Rost (Eds.) Latent trait and latent class models. New York: Plenum.

Corricher, N.; Cusmano, L. and Morrison, A. (2011) - "Competitive strategies and innovation modes in KIBS: Evidence from Lombardy", University of Padua, 18-19 March.

Fitjar, R., Rodriguez-Pose, A. (2013)- "Firm collaboration and modes of innovation in Norway", in Resarch Policy, 42, 128-138.

Fuller-Love, Nerys (2009) - "Formal and informal networks in small business in the media industry", in International Entrepreneurship Management Journal, 5:271-284.

Gokhberg, Leonid; Kuznetsova, Tatiana and Roud, Vitaliy (2012) - "Exploring Innovation Modes of Russian Companies: what does the diversity of actors mean for policymaking?", in Basic Research Program, Working Papers. WP BRP 01/STI/2012.

Hudson, Ray (1999) - "The learning Economy, the Learning Firm and the Learning Region: A Sympathetic Critique of the Limits of Learning”, in European Urban and Regional Studies, 6 (1), p. 59-72.

Jensen et al. (2007) - "Forms of knowledge and modes of innovation", in Research Policy, (36), p. 680-693.

Lorenz E. and Lundvall, B.-A. (eds.) (2006) - How Europe's Economies Learn: Coordinating Competing Models", Oxford University Press, New York. ISBN: 978-0-19-920319-2.

Lundvall, Ben-Äke (2007) - "National Innovation Systems - Analytical Concept and Development Tool”, in Industry and Innovation, Vol. 14, n. ${ }^{\circ}$ 1: 95-119.

DINÂMIA'CET - IUL, Centro de Estudos sobre a Mudança Socioeconómica e o Território ISCTE-IUL - Av. das Forças Armadas, 1649-026 Lisboa, PORTUGAL 
Marlon, Frenz and Lambert, Ray (2009) - "Exploring non-technological and Mixed Modes of Innovation Across Countries", in OECD - Innovation in Firms: A Microeconomic Perspective, OECD Publishing.

McCutcheon AC. (1987) - “Latent class analysis”. Beverly Hills: Sage Publications.

McLachlan, G. Peel, D. (2000) - “Finite Mixture Models”, New York. Wile.

Nunes, Sérgio and Lopes, Raul (2013) - "Firm's strategies of innovation and the effect of economic crisis" in $53^{\text {rd }}$ ERSA Congress, Regional Integration: Europe, the Mediterranean and the World Economy, 27-31 August, Palermo, Italy.

Nunes, Sérgio (2012) - “O papel do território no processo de inovação empresarial”. PHD Thesis. IUL-ISCTE, Lisbon, July.

Nunes, Sérgio and Lopes, Raul (2012a) - "The importance of external knowledge in the firm innovation process", in Bernhard, I. (ed.) 15th Uddevalla Symposium 2012, Entrepreneurship and Innovation Networks, Algarve University, Faro 14-16 June. Research reports 2012:02, University West, Sweden.

Nunes, Sérgio and Lopes, Raul (2012b) - "External knowledge, networks and the innovation process", in Bernhard, I. (ed.) 15th Uddevalla Symposium 2012, Entrepreneurship and Innovation Networks, Algarve University, Faro 14-16 June. Research reports 2012:01, University West, Sweden.

Parrilli, David; González, José and Peña, Iñaki (2012) - "Disentangling the relationship between learning modes, innovation types and firm performance: Evidence from Spain", in The Challenge of Regional development in a World of changing hegemonies: knowledge, competitiveness and austerity. International Conference on Regional Science, XXXVIII Reunión de Estudos Regionales - AECR. 22-23 November. Bilbao, Spain.

Parrilli, David and Elola, Aitziber (2011) - "The strength of science and technology drivers for SME innovation", in Small Business Economics, Vol. 39.(4), pp. 897-907.

Reis, José (2009) - “As relações inter-regionais em Portugal e o "efeito-capitalidade". Finisterra, XLIV, 88, 2009, pp. 25-36.

DINÂMIA'CET - IUL, Centro de Estudos sobre a Mudança Socioeconómica e o Território ISCTE-IUL - Av. das Forças Armadas, 1649-026 Lisboa, PORTUGAL 


\section{Firm Performance and Modes of Innovation}

Tödtling, Franz, Lehner, Patrick e Trippl, M. (2004) - "Knowledge intensive industries, networks, and collective learning", in 44th European Congress of the European Regional Science Association, 25-29 August, Universidade do Porto, Portugal.

Tödtling, Franz, Lehner, Patrick e Kaufmann, Alexander (2006) - "Do different Types of Innovation require different Kinds of Knowledge Interactions?", in $46^{\text {th }}$ European Congress of the European Regional Science Association, Agosto, Voglos, Grécia.

Žížalová, Pavla (2009) - "Emerging innovation modes and (regional) innovation systems in the Czech Republic", TIK WP on Innovation Studies. N. ${ }^{\circ} 20090102$. 
APPENDIX

Table A1 - Concomitants variables and categories

\begin{tabular}{|c|c|}
\hline Variables & Categories \\
\hline \multirow{5}{*}{ Level of technological intensity } & Low technology \\
\hline & Medium-low technology \\
\hline & Medium-high technology \\
\hline & High technology \\
\hline & Knowledge services \\
\hline \multirow{3}{*}{ Nuts III regions } & Greater Lisbon and Setubal Peninsula \\
\hline & Greater Porto \\
\hline & Pinhal Litoral \\
\hline \multirow{3}{*}{ Firm size } & Micro \\
\hline & SME \\
\hline & Large \\
\hline
\end{tabular}

Table A2 - Model 3 estimation: three latent classes

\begin{tabular}{|c|c|c|c|c|c|}
\hline & Cluster1 & Cluster2 & Cluster3 & & Total \\
\hline Cluster Size & 0,6712 & 0,2005 & 0,1282 & p-value & 1,000 \\
\hline Variables & & & & & \\
\hline Multidisciplinary groups & & & & 0,0160 & \\
\hline Irrelevant & 0,0871 & 0,0003 & 0,0349 & & 0,0630 \\
\hline Low Importance & 0,1071 & 0,2256 & 0,1667 & & 0,1385 \\
\hline Indifferent & 0,3225 & 0,6107 & 0,4593 & & 0,3980 \\
\hline Very Important & 0,3447 & 0,1629 & 0,2398 & & 0,2947 \\
\hline Fundamental & 0,1386 & 0,0005 & 0,0993 & & 0,1058 \\
\hline Quality circles/groups & & & & 0,0001 & \\
\hline Irrelevant & 0,1066 & 0,1789 & 0,0263 & & 0,1108 \\
\hline Low Importance & 0,0617 & 0,2148 & 0,244 & & 0,1159 \\
\hline Indifferent & 0,0981 & 0,2084 & 0,0836 & & 0,1184 \\
\hline Very Important & 0,5991 & 0,2545 & 0,5729 & & 0,5265 \\
\hline Fundamental & 0,1345 & 0,1435 & 0,0731 & & 0,1285 \\
\hline Collective proposals & & & & 0,0000 & \\
\hline Irrelevant & 0,1051 & 0,0429 & 0,1488 & & 0,0982 \\
\hline Low Importance & 0,1131 & 0,4234 & 0,0018 & & 0,1612 \\
\hline Indifferent & 0,2394 & 0,2395 & 0,1796 & & 0,2317 \\
\hline Very Important & 0,3993 & 0,1674 & 0,4776 & & 0,3627 \\
\hline Fundamental & 0,1431 & 0,1268 & 0,1922 & & 0,1461 \\
\hline Integrated functions & & & & 0,0005 & \\
\hline Irrelevant & 0,0376 & 0,0129 & 0,0189 & & 0,0302 \\
\hline Low Importance & 0,0001 & 0,0269 & 0,2718 & & 0,0403 \\
\hline Indifferent & 0,2990 & 0,2543 & 0,6694 & & 0,3375 \\
\hline Very Important & 0,3847 & 0,6802 & 0,0054 & & 0,3955 \\
\hline Fundamental & 0,2786 & 0,0257 & 0,0345 & & 0,1965 \\
\hline Less well differentiated groups & & & & 0,0130 & \\
\hline
\end{tabular}

DINÂMIA'CET - IUL, Centro de Estudos sobre a Mudança Socioeconómica e o Território ISCTE-IUL - Av. das Forças Armadas, 1649-026 Lisboa, PORTUGAL

Tel. 210464031 - Extensão 293100 E-mail: dinamia@iscte.pt www.dinamiacet.iscte.pt 


\section{Firm Performance and Modes of Innovation}

\begin{tabular}{l|lll|l}
\hline Irrelevant & 0,1085 & 0,0886 & 0,0007 & 0,0907 \\
Low Importance & 0,1427 & 0,4251 & 0,0017 & 0,1814 \\
Indifferent & 0,5270 & 0,4701 & 0,7496 & 0,5441 \\
Very Important & 0,2034 & 0,0025 & 0,2479 & 0,1688 \\
Fundamental & 0,0184 & 0,0137 & 0,0001 & 0,0151 \\
\hline
\end{tabular}

Source: Authors' own compilation

Table A2 - Model 3 estimation: three latent classes (cont.)

\begin{tabular}{|c|c|c|c|c|c|}
\hline & Cluster1 & Cluster2 & Cluster3 & & Total \\
\hline Cluster Size & 0,6712 & 0,2005 & 0,1282 & pvalue & 1,000 \\
\hline Variables & & & & & \\
\hline External cooperation & & & & 0,0000 & \\
\hline Irrelevant & 0,1879 & 0,0338 & 0,0443 & & 0,1385 \\
\hline Low Importance & 0,1057 & 0,1838 & 0,1608 & & 0,1285 \\
\hline Indifferent & 0,4211 & 0,0952 & 0,6534 & & 0,3854 \\
\hline Very Important & 0,2852 & 0,6872 & 0,1415 & & 0,3476 \\
\hline R\&D Department & & & & 0,0000 & \\
\hline Irrelevant & 0,1448 & 0,1541 & 0,1011 & & 0,1411 \\
\hline Low Importance & 0,0374 & 0,5834 & 0,1473 & & 0,1612 \\
\hline Indifferent & 0,4217 & 0,0231 & 0,2918 & & 0,3249 \\
\hline Very Important & 0,1816 & 0,0008 & 0,1881 & & 0,1461 \\
\hline Fundamental & 0,2145 & 0,2386 & 0,2716 & & 0,2267 \\
\hline External Financing & & & & 0,0000 & \\
\hline Irrelevant & 0,2900 & 0,0568 & 0,1225 & & 0,2217 \\
\hline Low Importance & 0,3546 & 0,4498 & 0,1899 & & 0,3526 \\
\hline Indifferent & 0,1537 & 0,3671 & 0,6047 & & 0,2544 \\
\hline Very Important & 0,2017 & 0,1262 & 0,0829 & & 0,1713 \\
\hline Innovation new to the market & & & & 0,0150 & \\
\hline Irrelevant & 0,0037 & 0,0000 & 0,0000 & & 0,0025 \\
\hline Low Importance & 0,0344 & 0,0585 & 0,0818 & & 0,0453 \\
\hline Indifferent & 0,4641 & 0,6510 & 0,3234 & & 0,4836 \\
\hline Very Important & 0,3432 & 0,1675 & 0,5939 & & 0,3401 \\
\hline Fundamental & 0,1545 & 0,1229 & 0,0009 & & 0,1285 \\
\hline Predominance of Innovation Activities & & & & 0,0001 & \\
\hline Knowledge production & 0,1264 & 0,2983 & 0,1678 & & 0,1662 \\
\hline Knowledge transformation & 0,1184 & 0,2441 & 0,2747 & & 0,1637 \\
\hline Product Placement in the Market & 0,7552 & 0,4576 & 0,5576 & & 0,6700 \\
\hline Knowledge context & & & & 0,0000 & \\
\hline Territorial & 0,1801 & 0,6882 & 0,2775 & & 0,2947 \\
\hline Global & 0,8199 & 0,3118 & 0,7225 & & 0,7053 \\
\hline Learning and interaction mechanisms & & & & 0,0420 & \\
\hline Formal & 0,3226 & 0,3467 & 0,5585 & & 0,3577 \\
\hline Informal & 0,6774 & 0,6533 & 0,4415 & & 0,6423 \\
\hline
\end{tabular}

Source: Authors' own compilation

DINÂMIA'CET - IUL, Centro de Estudos sobre a Mudança Socioeconómica e o Território ISCTE-IUL - Av. das Forças Armadas, 1649-026 Lisboa, PORTUGAL

Tel. 210464031 - Extensão 293100 E-mail: dinamia@iscte.pt www.dinamiacet.iscte.pt 


\section{Firm Performance and Modes of Innovation}

Table A2 - Model 3 estimation: three latent classes (cont.)

\begin{tabular}{|c|c|c|c|c|c|}
\hline & Cluster1 & Cluster2 & Cluster3 & & Total \\
\hline Cluster Size & 0,6712 & 0,2005 & 0,1282 & pvalue & 1,000 \\
\hline Characterization variables & & & & \multirow{7}{*}{0,0180} & \\
\hline Level of technological intensity & & & & & \\
\hline Low technology & 0,3251 & 0,1361 & 0,1081 & & 0,2594 \\
\hline Medium-low technology & 0,2431 & 0,3385 & 0,4185 & & 0,2846 \\
\hline Medium-high technology & 0,1507 & 0,1822 & 0,3020 & & 0,1763 \\
\hline High technology & 0,0836 & 0,0635 & 0,0720 & & 0,0781 \\
\hline Knowledge services & 0,1976 & 0,2796 & 0,0994 & & 0,2015 \\
\hline Nuts III regions & & & & \multirow[t]{4}{*}{0,1800} & \\
\hline Greater Lisbon and Setubal Peninsula & 0,6050 & 0,5565 & 0,4406 & & 0,5743 \\
\hline Greater Porto & 0,2280 & 0,2643 & 0,3780 & & 0,2544 \\
\hline Pinhal Litoral & 0,167 & 0,1792 & 0,1814 & & 0,1713 \\
\hline Firm size & & & & \multirow[t]{4}{*}{0,0065} & \\
\hline Micro & 0,0002 & 0,3383 & 0,0199 & & 0,0705 \\
\hline SME & 0,8486 & 0,6041 & 0,8406 & & 0,7985 \\
\hline Large & 0,1513 & 0,0577 & 0,1396 & & 0,1310 \\
\hline
\end{tabular}

Source: Authors' own compilation

Table A3 - description of the variables used in the models

\begin{tabular}{|c|c|c|}
\hline \multirow{2}{*}{ MODELS } & \multicolumn{2}{|c|}{ VARIABLES } \\
\hline & DEPENDENT & \multirow{6}{*}{$\begin{array}{l}\text { INNOVATION MODES } \\
\text { 1. Low Learning DUI } \\
\text { 2. Moderate DUI/STI } \\
\text { 3. Moderate DUI }\end{array}$} \\
\hline Model 1 & $\begin{array}{l}\text { Innovation Product } \\
0-\mathrm{No} \\
1-\mathrm{Yes}\end{array}$ & \\
\hline Model 2 & $\begin{array}{l}\text { Innovation Process } \\
0-\mathrm{No} \\
1-\mathrm{Yes} \\
\end{array}$ & \\
\hline Model 3 & $\begin{array}{l}\text { Aggregated Innovation Performance } \\
\text { 1. Zero type of innovation } \\
\text { 2. One type of innovation } \\
\text { 3. Two types of innovation } \\
\text { 4. Three types of innovation } \\
\text { 5. Four types of innovation }\end{array}$ & \\
\hline Model 4 & $\begin{array}{l}\text { Growth of Turnover } \mathbf{0 7 - 0 8}(\%) \\
\text { 1. } 05-10 \\
\text { 2. } 11-15 \\
\text { 3. } 16-20 \\
\text { 4. } 21-30 \\
\text { 5. } 31-50 \\
\text { 6. }>50\end{array}$ & \\
\hline Model 5 & $\begin{array}{l}\text { Impact of Economic Crisis } \\
\text { 1. Low importance } \\
\text { 3. Very important } \\
\text { 5. Fundamental } \\
\text { urce: Authors' own compilation }\end{array}$ & \\
\hline
\end{tabular}

DINÂMIA'CET - IUL, Centro de Estudos sobre a Mudança Socioeconómica e o Território ISCTE-IUL - Av. das Forças Armadas, 1649-026 Lisboa, PORTUGAL

Tel. 210464031 - Extensão 293100 E-mail: dinamia@iscte.pt www.dinamiacet.iscte.pt 
Table A4 - Innotion modes, firm performance and economic crisis: estimation results (odds ratio)

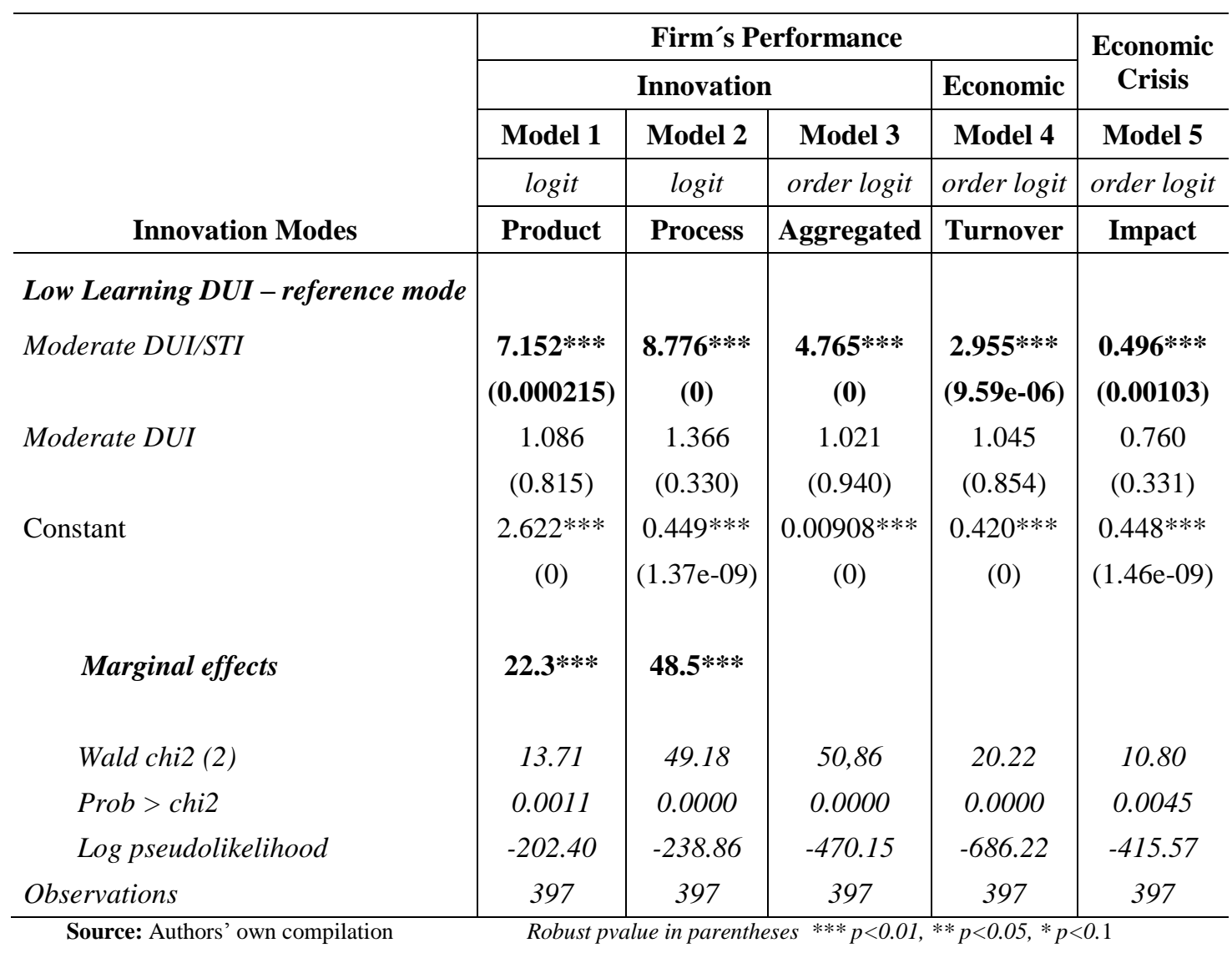

Table A4 - Model 3: Marginal Effects (cont.)

\begin{tabular}{|c|c|c|c|c|c|c|}
\hline \multirow{2}{*}{$A I P$} & \multirow{2}{*}{$\begin{array}{l}\text { Coefficients } \\
\text { (Odds Ratio) }\end{array}$} & \multicolumn{5}{|c|}{ Aggregated Innovation Performance (marginal effects) } \\
\hline & & no type & one type & two types & three types & four types \\
\hline Low Learning DUI - reference mode & & & & & & \\
\hline $\begin{array}{l}\text { Moderate DUI/STI } \\
\text { Moderate DUI }\end{array}$ & $\begin{array}{c}\mathbf{4 . 7 6 5} * * * \\
(\mathbf{0 . 0 0 0 )} \\
1.021 \\
(0.940)\end{array}$ & $-0.7 *$ & $-15.5 * * *$ & $-20.5 * * *$ & $26.1 * * *$ & $10,5 * * *$ \\
\hline
\end{tabular}

Table A4 - Model 4: Marginal Effects (cont.)

\begin{tabular}{c|c|c|c|c|c|c|c}
\hline \multirow{2}{*}{ Turnover class } & \multirow{2}{*}{$\begin{array}{c}\text { Coefficients } \\
\text { (Odds Ratio) }\end{array}$} & \multicolumn{5}{|c}{ Turnover class (marginal effects) } \\
\cline { 3 - 7 } & & $05-10$ & $11-15$ & $16-20$ & $21-30$ & $31-50$ & $>50$ \\
\hline Low Learning DUI - reference mode & & & & & & & \\
Moderate DUI/STI & $\mathbf{2 . 9 5 5 * * *}$ & $\mathbf{- 1 7 . 0 * * * *}$ & $\mathbf{- 6 . 9 * * *}$ & $\mathbf{- 2 . 4 * * *}$ & $\mathbf{3 . 0} * * *$ & $\mathbf{6 , 8 * * *}$ & $\mathbf{1 6 , 5 * * * *}$ \\
Moderate DUI & $\mathbf{9 . 5 9 e - 0 6 )}$ & & & & & \\
& 1.045 & & & & & & \\
\hline
\end{tabular}

DINÂMIA'CET - IUL, Centro de Estudos sobre a Mudança Socioeconómica e o Território ISCTE-IUL - Av. das Forças Armadas, 1649-026 Lisboa, PORTUGAL

Tel. 210464031 - Extensão 293100 E-mail: dinamia@iscte.pt www.dinamiacet.iscte.pt 


\section{Firm Performance and Modes of Innovation}

Table A4 - Model 5: Marginal Effects (cont.)

\begin{tabular}{|c|c|c|c|c|}
\hline \multirow[t]{2}{*}{ ICI } & $\frac{\text { Coefficients }}{\text { Odds Ratio }}$ & \multicolumn{3}{|c|}{$\begin{array}{c}\text { Impact of Crisis on Innovation } \\
\text { (marginal effects) }\end{array}$} \\
\hline & & low relevance & very important & fundamental \\
\hline Low Learning $D U I$ & & & & \\
\hline $\begin{array}{l}\text { Moderate DUI/STI } \\
\text { Moderate DUI }\end{array}$ & $\begin{array}{c}\mathbf{0 . 4 9 6} * * * \\
(\mathbf{0 . 0 0 1 0 3}) \\
0.760 \\
(0.331)\end{array}$ & $0,16 * * *$ & $-0,06 * * *$ & $-10,2 * * *$ \\
\hline
\end{tabular}

Table A5 - Innovation modes and firm performance: estimation results with control variables

\begin{tabular}{|c|c|c|}
\hline \multicolumn{3}{|c|}{ Innovation Modes - Moderate DUI (reference) } \\
\hline $\begin{array}{c}\text { Firm's } \\
\text { Performance } \\
\end{array}$ & Low Learning DUI & Moderate DUI/STI \\
\hline Product Innovation & $\begin{array}{l}\text { - In MLT is better than the } \\
\text { reference mode }\end{array}$ & - SME; MLT \\
\hline Process Innovation & $\begin{array}{l}\text { - In Oporto region is } \\
\text { worst than the reference } \\
\text { mode }\end{array}$ & $\begin{array}{l}\text { - SME; All regions; } \\
\text { MLT and MHT }\end{array}$ \\
\hline $\begin{array}{l}\text { Aggregated } \\
\text { Innovation }\end{array}$ & $\begin{array}{l}\text { - In } \mathrm{KS} \text { is worst than the } \\
\text { reference mode }\end{array}$ & $\begin{array}{l}\text { - SME; Lisbon and } \\
\text { Oporto; MLT and } \\
\text { MHT }\end{array}$ \\
\hline Economic & $\begin{array}{l}\text { - In LT is worst than the } \\
\text { reference mode } \\
\text { - In MHT is better than } \\
\text { the reference mode }\end{array}$ & $\begin{array}{l}\text { - Lisboa and Leiria; } \\
\text { LT, MLT and MHT }\end{array}$ \\
\hline
\end{tabular}

Source: Authors' own compilation

DINÂMIA'CET - IUL, Centro de Estudos sobre a Mudança Socioeconómica e o Território ISCTE-IUL - Av. das Forças Armadas, 1649-026 Lisboa, PORTUGAL 